\title{
Inter- and Intracellular Luminal Formation in Porcine Thyroid Tissues Cultured in a Collagen Substrate*
}

\author{
Keisuke Yamashita, Hisao Fujita, Koichi KitajIma and Yoshio NishII \\ Department of Anatomy, Osaka University Medical School, Osaka, Japan \\ Received September 1, 1988
}

\begin{abstract}
Summary. Porcine thyroid epithelial cells, isolated and cultured on a type I collagen substrate, formed a monolayered sheet. When the apical surface of the monolayer was further covered with the same collagen substrate, the epithelial cells migrated and formed intercellular follicular lumen-like structures. In addition, a true intracellular follicular lumen sometimes appeared, especially in cells of the monolayer region. It was proved by serial sections that the intracellular follicular lumina, 1-5 $\mu \mathrm{m}$ in diameter, lined by rather long microvilli and stained for PAS, had no openings to the extracellular space. The intracellular lumina are presumed to fuse with each other to form an intercellular follicnear lumen, or fuse with the preformed intercellular follicular lumen. Autoradiographic studies using ${ }^{125} I$ revealed that iodination of thyroglobulin takes place in the peripheral region of both intracellular and intercellular follicular lumina.
\end{abstract}

In a previous paper (KITAJIMA et al., 1987), we reported on the formation mechanism of the follicle-like cavity from a monolayer of porcine thyroid cells cultured in a collagen sandwich. In such a case, the folliclelike cavities have been known to appear generally between the cells of the upper layer and those of the lower layer, which were formed by the proliferation and migration of the monolayered cells (KITAJIMA et al., 1987). In addition, it has become clear that an intracellular follicular lumen sometimes appears in cultured cell cytoplasm, later opening to the intercellular follicular cavity. The present paper deals with the fine structural and histochemical aspects of the intercellular and intracellular follicular lumina occurring in cultured thyroid tissues. The results may prove useful toward an understanding of the origin and development of the follicular lumina in the thyroid gland.

\section{MATERIALS AND METHODS}

\section{Collagen gel solution}

A solution of type I collagen (Cellmatrix I-P, Nitta Gelatin Co., Osaka, Japan), extracted from rat tail tendon collagen and solubilized at $\mathrm{pH} 3.0$ by pepsin was used for the present work. Before use, eight volumes of Cellmatrix I-P, one volume of 10X Eagle's minimum essential medium (MEM) (Nissui Co., Tokyo, Japan), one volume of reconstitution buffered solution containing $200 \mathrm{mM}$ HEPES, $260 \mathrm{mM} \mathrm{NaHCO}$, $50 \mathrm{mM} \mathrm{NaOH}$, and one volume of heat-inactivated fetal calf serum were mixed, neutralized to $\mathrm{pH} 7.4$, and incubated at $37^{\circ} \mathrm{C}$ in a water-saturated incubator to form a solid gel.

Isolation and culture of porcine thyroid epithelial cells Porcine thyroid glands, obtained from a local slaughter house, were minced in Hanks' balanced salt solution (BSS) after deprivation of the connective tissues and capsules. To digest the interfollicular connective tissue elements, the tissue fragments were incubated in Eagle's MEM containing $0.1 \%$ collagenase (Cooper Biomedical Inc., type II) for $1 \mathrm{hr}$ at $37^{\circ} \mathrm{C}$. After rinsing in $0.02 \%$ EDTA $/ \mathrm{Ca}^{2+}$., $\mathrm{Mg}^{2+}$-free phosphate buffered saline solution (CMF-PBS), they were further digested in $0.2 \%$ trypsin (Difco) / $0.02 \%$ EDTA/ CMF-PBS for $30 \mathrm{~min}$ at $37^{\circ} \mathrm{C}$ to obtain single cells. The suspensions of the cells were cultured in plastic culture dishes (Falcon, $35 \mathrm{~mm}$ in diameter) in a medium of $15 \mathrm{mM}$ HEPES/Eagle's MEM/10\% heatinactivated fetal calf serum/antibiotics (penicillin, streptomycin, and amphotericin B) supplemented with $10 \mu \mathrm{g} / \mathrm{ml}$ insulin, $5 \mu \mathrm{g} / \mathrm{ml}$ dexamethazone, and 5 $\mathrm{mI}$. U./ml thyroid stimulating hormone (TSH).

Seven days after culturing, the cells were transferred with the trypsin solution and seeded on a preformed sheet of type I collagen gel in other plastic dishes. Twenty four hours after incubation on the collagen

*This study was supported by grants from the Ministry of Education, Science and Culture, Japan. 
gel sheet, the apical surface of the cell sheet was further covered with the same collagen solution, which soon formed a gel at $37^{\circ} \mathrm{C}$. The culture medium described above was renewed every three days in the culture dishes to nourish the cells and to keep the gel from drying.

\section{Culture in floating gel}

One week after the epithelial cells were covered with collagen gel on both sides, the entire collagen gel was stripped off from the plastic culture dish with a needle $(27 \mathrm{G})$. The epithelial cells were further incubated for a week as a floating gel in the culture medium, which bathed both sides of the cell layer.

\section{Conventional light and electron microscopy}

The thyroid epithelial cells, covered on both sides with the collagen gel and incubated as a floating gel, were fixed overnight in situ at $4^{\circ} \mathrm{C}$ in $2.5 \%$ glutaraldehyde solution in $0.1 \mathrm{M}$ Millonig's phosphate buffer and then cut into small pieces ( $3 \mathrm{~mm}$ by $3 \mathrm{~mm}$ in size). The tissue blocks were post-fixed in $1.0 \% \mathrm{OsO}_{4}$ in $0.1 \mathrm{M}$ Millonig's phosphate buffer with sucrose for $1 \mathrm{~h}$ at $4^{\circ} \mathrm{C}$. After being stained en bloc with $3.0 \%$ uranyl acetate solution, they were dehydrated in a graded ethanol series and propylene oxide, and embedded in Epon mixture. Ultrathin sections cut in a Leichert Ultracut microtome and doubly stained with $3 \%$ uranyl acetate and Reynolds' lead citrate were observed in a JEOL 1200EX-type electron microscope. Serial sections ( $85 \mathrm{~nm}$ thick) were cut and observed in an electron microscope to examine the continuity of the follicle lumen.

For light microscopy, tissue blocks fixed in the glutaraldehyde solution were dehydrated in a graded ethanol series and embedded in JB-4 embedding medium (Polysciences Inc.).

\section{Autoradiography with ${ }^{125} I$}

For demonstration of the iodination site in the epithelial cells, an autoradiographic study was performed with radioactive iodine ( $\mathrm{Na}^{125} \mathrm{I}$, carrier free, Du Pont/ NEM). Sheets of epithelial cells were incubated in the culture medium containing $50 \mu \mathrm{Ci}$ of ${ }^{125} \mathrm{I}$, for $30 \mathrm{sec}$, $1,2,10,30 \mathrm{~min}$ at $37^{\circ} \mathrm{C}$, and were then fixed in situ in $2.5 \%$ glutaraldehyde solution for autoradiography at the electron as well as light microscopic level.

For electron microscopic autoradiography, the sections on copper grids were dipped in the Ilford L-4 emulsion by the wire loop method. After exposure for two to four weeks, the sections were developed in Microdol X (Kodak), fixed in 10\% sodium thiosulfate solution, and observed in an electron microscope after double staining.

\section{Immunohistochemistry}

Thyroid epithelial cells cultured for 2 weeks in the collagen substrate were fixed in $4 \%$ paraformaldehyde solution for $12 \mathrm{~h}$ at $4{ }^{\circ} \mathrm{C}$, and rinsed in $10 \%, 15 \%$, and $20 \%$ sucrose-PBS solutions for $4 \mathrm{~h}$ each. Cryosections cut in a Leitz 1720 cryostat and mounted on glass slides were incubated with rabbit anti-porcine thyroglobulin antibody $(1: 500)$ overnight at $4^{\circ} \mathrm{C}$, and then fluorescein isothiocyanate (FITC)-conjugated goat anti-rabbit IgG (Miles Scientific) for $1 \mathrm{hr}$ at room temperature. The sections were examined with a Nikon Fluorophoto microscope.

\section{RESULTS}

\section{Epithelial cells on a collagen gel}

When porcine thyroid cells were cultured on a collagen substrate for $24 \mathrm{~h}$, a monolayered sheet of epithelial cells was formed, as observed under a phase contrast microscope. The monolayered cell expressed cell polarity with its apical surface facing the culture medium and with its basal surface facing the collagen substrate. A zonula occludens was observed at the uppermost part of the lateral plasma membrane.

\section{Epithelial cells in a collagen gel}

When the apical surface of the monolayer was also covered with the collagen substrate, and both sides of the epithelial sheet were facing the collagen gel, some of the epithelial cells began to migrate, and formed a two-cell layer over one or two days. Intercellular lumina, sealed by junctional complexes, and of variable size and shape, appeared between the epithelial cells. Microvilli and pseudopod-like structures were noticed. The intercellular follicular lumina were immunostained with an antibody against porcine thyroglobulin (Fig. 1a).

In addition to the intercellular lumina, an intracellular follicle-like lumen appeared in a few cells during the two weeks after both sides of the cell sheet were covered with the collagen substrate. In order to clarify whether this lumen was truly intracellular in location or not, serial sections were examined (Fig. $2 \mathrm{a}, \mathrm{b})$. It was clearly demonstrated that some of the intracellular follicle-like lumina did not communicate with the extracellular space. In other words, true intracellular lumina definitely exist in some of these cultured cells. Sometimes features showing the fusion of the intercellular lumina with each other, and also the opening of the intracellular lumen to the preformed intercellular follicular lumen were noticed (Figs. $3 \mathrm{a}, \mathrm{b})$. Each intracellular lumen, 1-5 $\mu \mathrm{m}$ in diameter, 
showed relatively long microvilli and contained amorphous materials. The core of the microvilli was filled with bundles of microfilaments. These intracellular lumina were more often seen in those cells which remained as a monolayer, while intercellular follicular lumina were often observed between the cells of two-cell layers. There were electron-dense granules and electron-lucent vesicles in the cytoplasm around the intracellular follicular lumina. The Golgi apparatus was well-developed and many profiles of

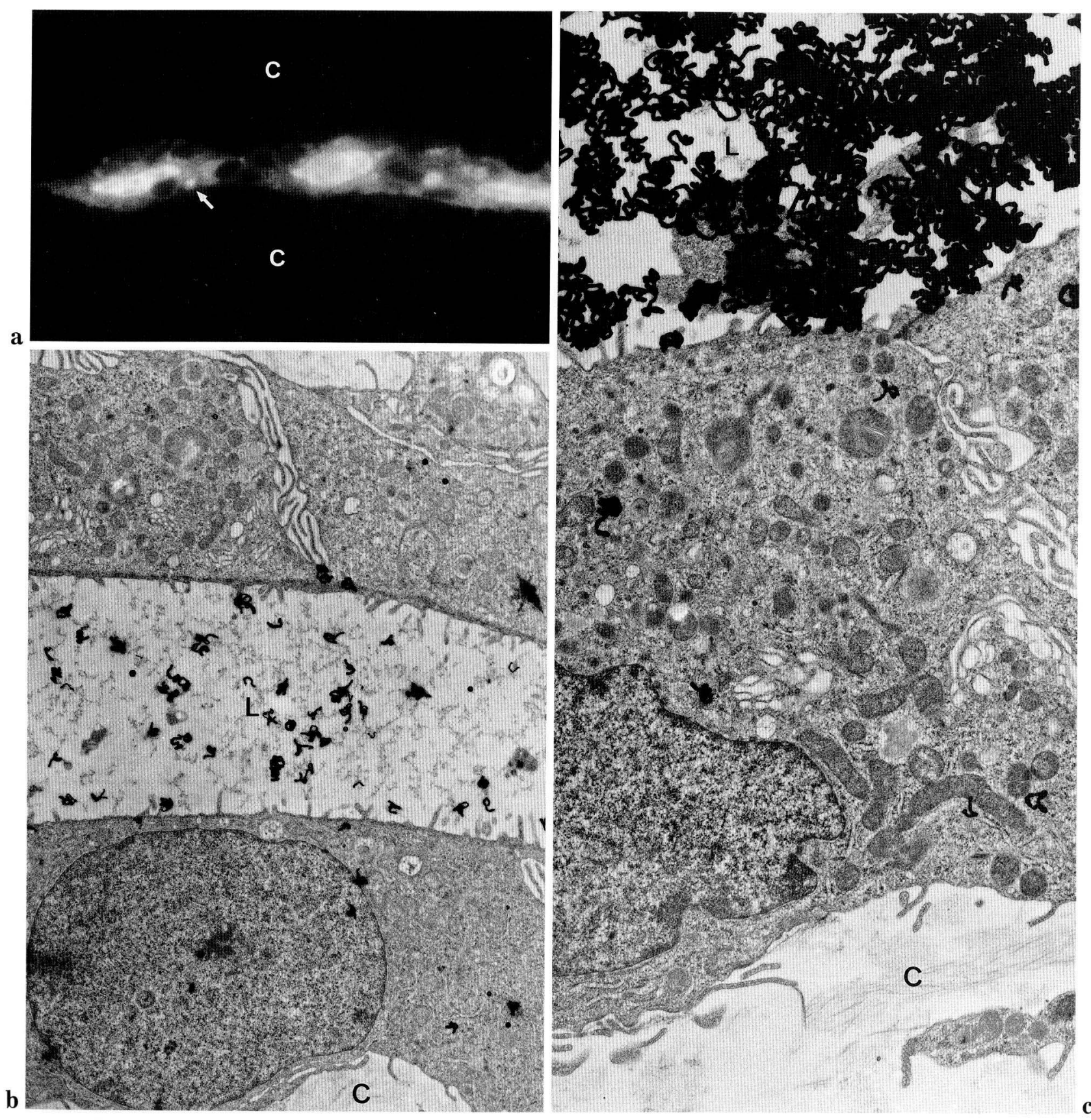

Fig. 1. Intercellular follicular lumina appearing after 2 weeks of culture in a floating collagen sandwich $(C)$. a. Immunofluorescence staining for thyroglobulin. Positive reactions are seen in the follicle-like lumina and cytoplasmic dots (arrow). $\times 600$. b. and c. Electron microscopic autoradiographs of ${ }^{125} \mathrm{I} 10 \mathrm{~min}(\mathbf{b})$ and $30 \mathrm{~min}$ (c) after adding the isotope into the culture medium. Silver grains are located in the intercellular follicular lumina $(L)$. b: $\times 8,300, \mathrm{c}: \times 12,000$ 


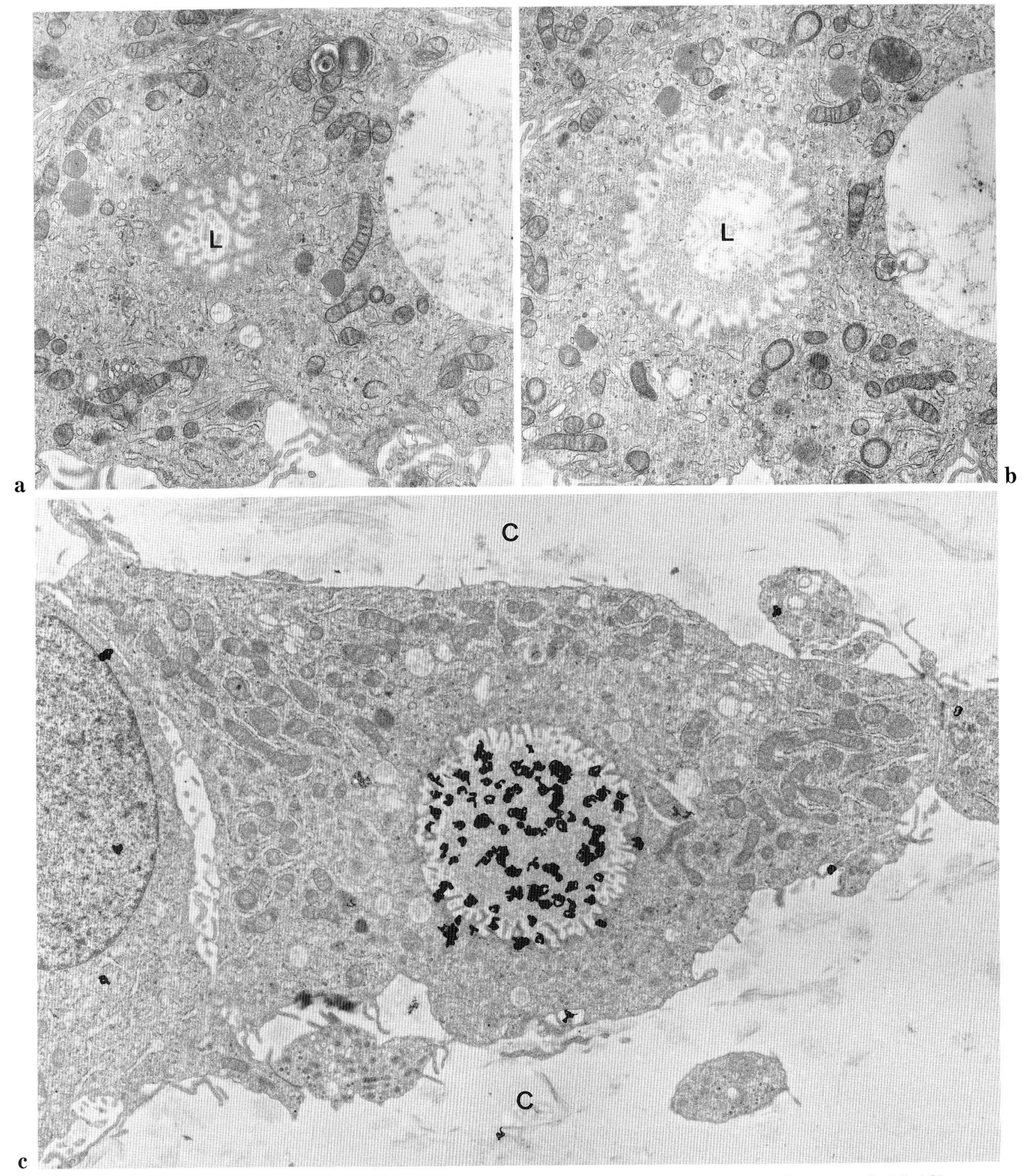

Fig. 2. Intracellular follicular lumina appearing after 2 weeks of culturing in a floating collagen sandwich $(C)$. a. and b. Serial sections of a lumen $(L)$ in the cytoplasm. a: $\times 9,100, b: \times 9,100$. c. Electron microscopic autoradiograph of ${ }^{125} \mathrm{I} 30 \mathrm{~min}$ after adding the isotope into the culture medium. Radioactive iodine is localized only in the intracellular follicular lumen. $\times 8,000$ 

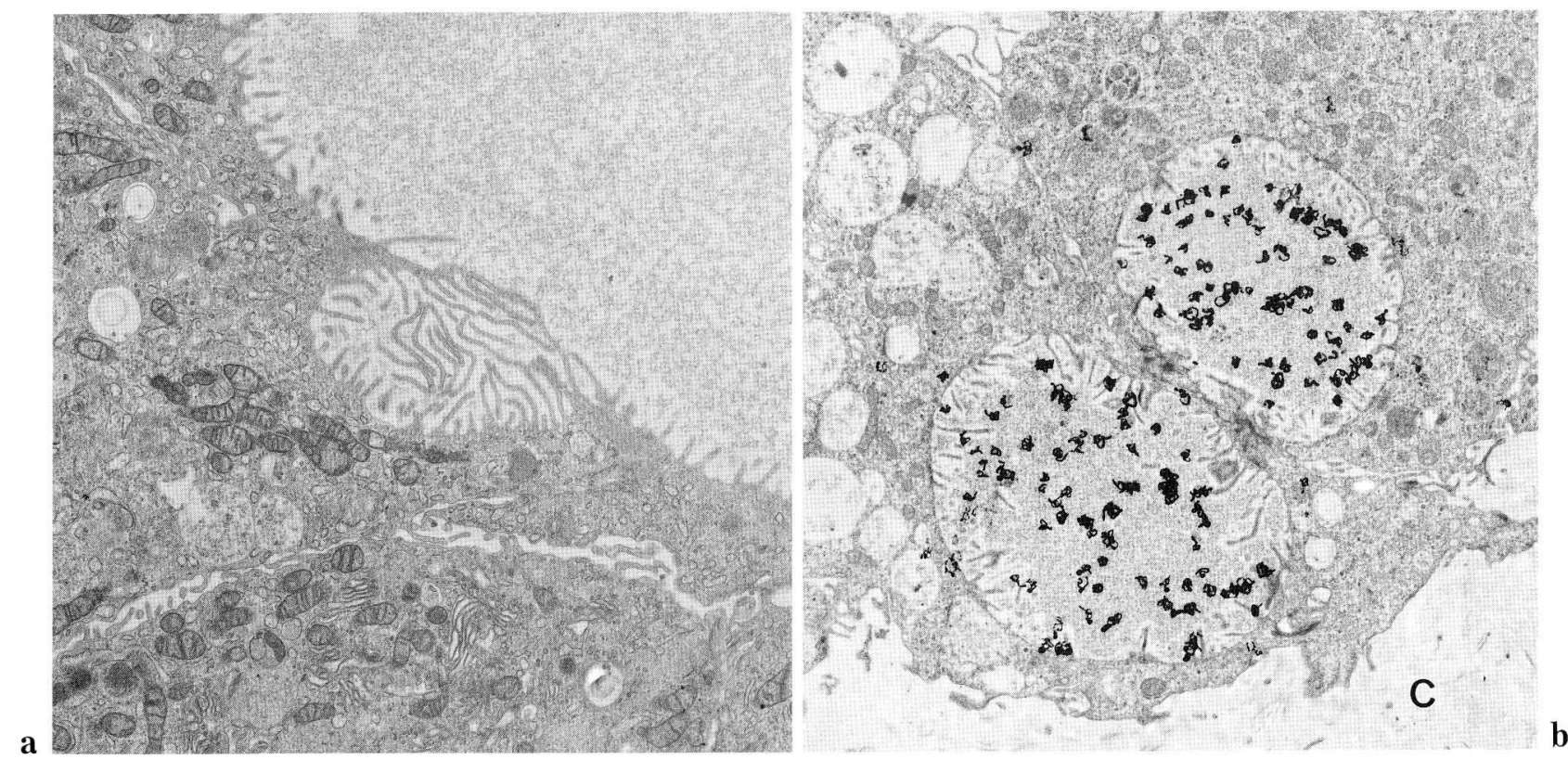

Fig. 3. a. Fusion of an intracellular follicular lumen with an intercellular follicular lumen in tissue cultured for 2 weeks in a floating collagen sandwich. Note the long microvilli in the intracellular lumen. $\times 12,000$. b. Electron microscopic autoradiograph of ${ }^{125} \mathrm{I} 30 \mathrm{~min}$ after adding the isotope into the culture medium. Note the fusion of two intracellular follicular lumina to make an intercellular follicle lumen in the tissue cultured for 2 weeks in a floating collagen sandwich $(C)$. Silver grains are localized in this lumen. $\times 6,000$

microtubules were seen near the intracellular follicular lumina. In regions where the intracellular lumina were fused with the preformed intercellular lumina, the microvilli of the intracellular follicular lumina were found to be longer than those of the intercellular ones (Fig. 3a).

\section{Histochemistry and ${ }^{125} I$ autoradiography}

Immunohistochemistry demonstrated that thyroglobulin was localized in both the intracellular and intercellular follicular lumina (Figs. 1b, c, 2c). Both types of lumina were also positive for PAS reaction. By autoradiography, silver grains for ${ }^{125} \mathrm{I}$ accumulated in the intercellular as well as intracellular follicular lumina at 10 and $30 \mathrm{~min}$ after incubation in the culture medium containing ${ }^{125} \mathrm{I}$ (Figs. 1b, c). The cytoplasm of the epithelial cells was not labeled for ${ }^{125} \mathrm{I}$ at all. The population density of the grains over the microvillous (peripheral) region was larger than that of the central part of the follicle lumina incubated for $10 \mathrm{~min}$, but the lumina were evenly filled with a large number of silver grains at $30 \mathrm{~min}$ after incubation in the medium containing ${ }^{125} \mathrm{I}$. The population density of the labeling over the intercellular lumina was almost the same as that over the intracellular follicular lumina.

\section{DISCUSSION}

In the present study, it was clearly demonstrated that intracellular lumen appeared in epithelial cells cultured in a floating collagen substrate. By the observation of serial sections and the occurrence of many long microvilli and thyroglobulin in them, the lumen was shown to be a true intracellular follicular lumen. From the findings displaying the fusion of the intracellular follicular lumina with each other or the opening of the intrafollicular lumen to the preformed intercellular follicular lumen, it can be easily understood that some intrafollicular lumina are fated to be fused with each other to form an intercellular lumen, while others are fused with the preformed intercellular follicular lumen. By our previous study, it was clear that the formation of intercellular follicular lumina between two layers of the cultured thyroid cells is a major factor in folliculogenesis (KITAJIMA et al., 1987), and the fusion of intracellular follicular lumina is considered to be of minor importance in making a follicular lumen. The intracellular lumina also have the function of helping the expansion of the preformed interfollicualr lumen through fusion with it. 
As to the origin and development of the follicular lumina in vivo, many studies have been performed using mammalian and chick embryos. Two ways have been established: one being that the primitive follicular lumen appears between neighboring two cells (HILFER, 1964; FuJiTA and TANIZAWA, 1966; TICE et al., 1977; IsHIMURA and FUJITA, 1979; REMY et al., 1980), the other being that the primitive follicular lumen originates from the fusion of intra-cellular lumina (ShePARD, 1968; Olin et al., 1970; CALVERT and PUSTERLA, 1973; REMY et al., 1983).

The occurrence of the intracellular lumina has been reported in the organ-cultured thyroid gland (REMY et al., 1983), in cultured open follicles (DENEF et al., 1980; EKHOLM and BJOERKMAN, 1984), and in cultured dispersed cells (EKHOLM and BJOERKMAN, 1984 ; RouSSET et al., 1985).

As to the mechanism of formation for the intracellular follicular lumen, it is suggested that it is derived from the coalescence of clear vesicles from the Golgi apparatus (REMY et al., 1983; EKHOLM and BJOERKMAN, 1984; RousSET et al., 1985).

Both intra- and intercellular follicular lumina were filled with amorphous PAS-positive materials and immunostained with an antibody against porcine thyroglobulin. The present autoradiographic study for ${ }^{125}$ I revealed that both lumina, especially their peripheral parts, are labeled with radioactive iodine. It is therefore reasonable to believe that iodination of thyroglobulin could take place in the peripheral part of the intracellular follicular lumina as well as in the intercellular ones. No grains for ${ }^{125}$ I were seen over the cytoplasm, so it is suggested that iodination of thyroglobulin takes place in our in vitro system only in the lumen and not in the cytoplasm, as shown in the thyroid follicles in vivo in the adult mouse (FUJITA, 1969, 1972, 1975). It is of interest that the intracellular lumina thereby take part in the storage of thyroglobulin and its iodination as do the intercellular lumina.

Acknowledgments. The authors wish to thank Dr. K. INOUE, Gunma University Institute of Endocrinology, for his generous gift of anti-thyroglobulin antibody.

\section{REFERENCES}

Calvert, R. and A. Pusterla: Formation of thyroid follicular lumina in rat embryos studied with serial fine sections. Gen. Comp. Endocrinol. 10: 584-597 (1973).

DENEF, J.-F., U. BJoERKMAN and R. EкHоLM : Structural and functional characteristics of isolated thyroid follicles. J. Ultrastr. Res. 71: 185-202 (1980).
EкноLм, R. and U. BJoerkman: Localization of iodine binding in the thyroid gland in vitro. Endocrinology 115: 1558-1567 (1984).

Fujita, H.: Studies on the iodine metabolism of the thyroid gland as revealed by electron microscopic autoradiography of ${ }^{125}$ I. Virchows Arch. Abt. B Zellpathol. 2: 265-279 (1969).

- : Morphological aspects on the site of iodination of thyroglobulin in the thyroid gland. Arch. Histol. Jap. 34: 109-141 (1972).

- : Fine structure of the thyroid gland. Int. Rev. Cytol. 40: 197-280 (1975).

Fujita, H. and Y. Tanizawa: Electron microscopic studies on the development of the thyroid gland of chick embryo. Z. Anat. Entw.-Gesch. 125: 132-151 (1966).

HILFER, S. R.: Early follicle formation in the embryonic chick thyroid. J. Morphol. 115: 135-152 (1964).

Ishimura, K. and H. Fujita: Development of cell-to-cell relationships in the thyroid gland of the chick embryo. Cell Tiss. Res. 198: 15-25 (1979).

Kitajima, K., K. Yamashita and H. Fujita: Fine structural aspects of follicle-like cavity formation from dispersed porcine thyroid cells cultured in a collagen substrate. Arch. Histol. Jap. 50: 113-127 (1987).

Olin, P., R. Екноцм and S. Almqvist: Biosynthesis of thyroglobulin related to the ultrastructure of the human fetal thyroid gland. Endocrinology 87: 1000-1014 (1970).

Remy, L., M. Michel-Bechet, A.-M. Athouel-Haon, S. Magre, C. Catlado and A. Jost: Development of the thyroid gland in the fetus in vivo. An ultrastructural and radioautographic study. Arch. Anat. Microsc. 69: 91-108 (1980).

Remy, L., B. Verrier, M. Michel-Bechet, E. Mazzella and A. M. Athouel-HaON: Thyroid follicular morphogenesis mechanism: Organ culture of the fetal gland as an experimental approach. J. Ultrastr. Res. 82: 283-295 (1983).

Rousset, B., M. Authelet, Y. Munari-Silem, J. Dumont and P. NEvE: Formation of intracellular lumina in dispersed pig thyroid cells. Eur. J. Cell Biol. 39: 432-442 (1985).

ShEPARD, T. H.: Development of the human fetal thyroid. Gen. Comp. Endocrinol. 10: 174-181 (1968).

Tice, L. W., R. L. CARTer and M. C. CAhill: Tracer and freeze fracture observations on developing tight junctions in fetal rat thyroid. Tiss. Cell 9: 395-417 (1977).

Prof. Hisao FujiTa Department of Anatomy Osaka University Medical School 4-3-57, Nakanoshima, Kitaku, Osaka, 530 Japan

藤田尚男 530 大阪市北区中之島 4-3-57 大阪大学医学部 解剖学教室 